\title{
The Challenges of Digitalization in the Public Sector: Cloud Computing
}

\author{
Alina CRîșMARIU (ȘOMîTCĂ), Ec. PhD, Sorin ȘOMîTCĂ, Ec. PhD \\ "Ştefan cel Mare" University of Suceava, Romania
}

\begin{abstract}
Information technology is a reality of our days, and the future means digitalization. The public sector cannot be absent from this natural evolution of things.

Cloud computing technology is defined as a service that uses cloud accounting software available to users and can be accessed from anywhere and does not require hardware, and its development brings a new evolution in the information-accounting system: cloud accounting. This article focuses on the implementation of cloud computing in the public sector, and qualitative research highlights the benefits and challenges of integrating this technology in the public domain. The result of the study can be a starting point for the implementation of cloud computing technology in the public sector.
\end{abstract}

Key terms: digitalization, cloud computing, accounting, the public sector

JEL Classification: O33, Q55, H83

To cite this article: Alina Crîșmariu (Șomîtcă), Sorin Șomîtcă, The Challenges of Digitalization in the Public Sector: Cloud Computing, CECCAR Business Review, No 12/2021, pp. 65-72, DOI: http://dx.doi.org/10.37945/cbr.2021.12.08

\section{Introduction}

In the age of technology, the performance of entities depends on their ability to invest in new technologies to the same extent that other factors determine the exploitation of business opportunities and the adaptation of their business processes. According to the accounting literature, accounting change factors can be divided into three broad categories, namely: (1) growing globalization, (2) improved information technologies and (3) improved production methods (Burns et al., 1999; Russel and Siegel, 1999; Scapens et al., 2003).

Accounting is the science, the language through which the performance of companies is measured. It has undergone many changes over time, constantly adapting to the economic context. The introduction of digital technology and accounting programs has had the effect of improving the processes of accounting practice. Due to the significant amount of information and processing time required, accounting software has become an imperative in practice, helping to streamline business and reduce working time. Technological changes have influenced the entities, but also the accounting departments, which have had to adapt to digitalization and the Internet.

The digitalization of the public sector is an intensely debated topic in the current literature. Performing a search on the Web of Science Core Collection by using the keywords digitalization and public sector, we identified 316 publications. By analyzing the obtained data, we can observe that 29 articles are from the public administration domain, as shown in Figure 1. 

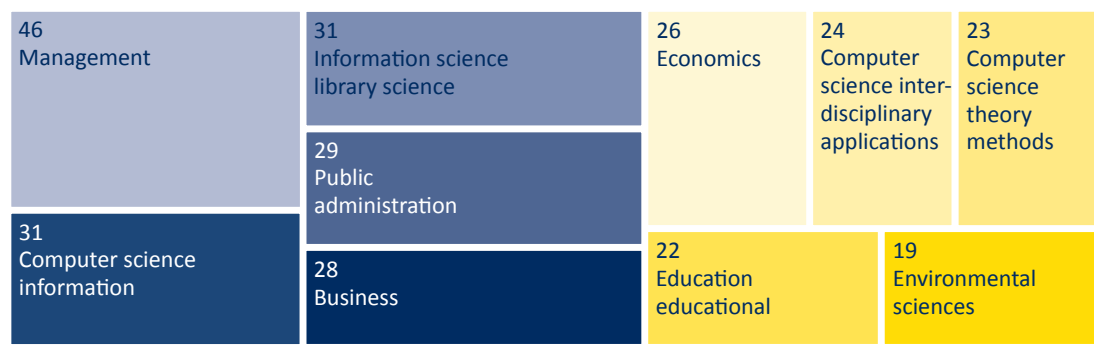

Figure 1. Digitalization in the public sector in Web of Science

Source: Own processing in https://wcs-webofknowledge-com.am.e-nformation.ro/RA/analyze.do.

With regard to the countries where the issue of digitalization is intensely debated, Russia, Germany and Finland are on the first three places, as can be seen in Figure 2 .

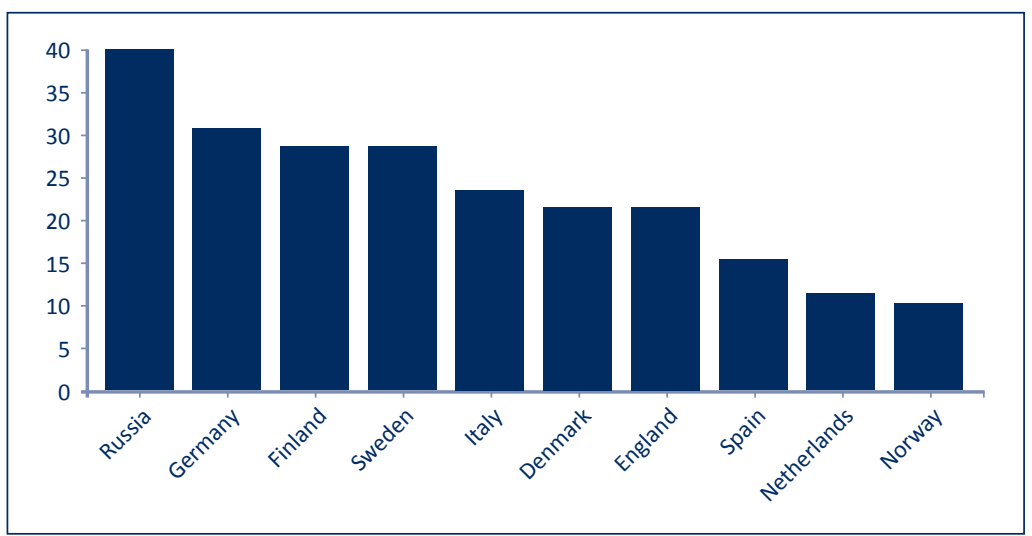

Figure 2. Research directions on digitalization in the public sector by country

Source: Own processing in https://wcs-webofknowledge-com.am.e-nformation.ro/RA/analyze.do.

Analysing the years in which the subject of digitalization appears in the public sector, we could notice that the highest research output on this topic is in 2019, followed at a short distance by the years 2020 and 2021.

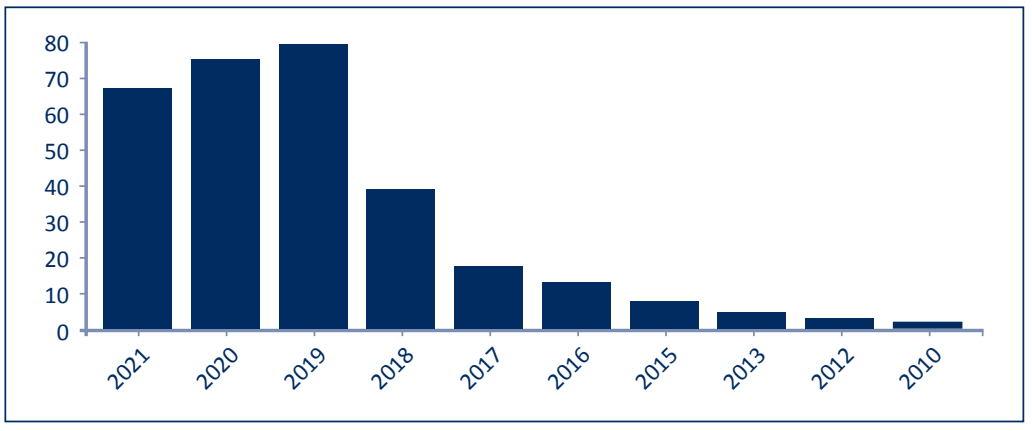

Figure 3. Research directions on digitalization in the public sector by year

Source: Own processing in https://wcs-webofknowledge-com.am.e-nformation.ro/RA/analyze.do.

In the literature there are a number of studies focusing on the implementation of cloud computing. Cloud computing has a significant influence on all areas and it has been predicted to be the platform on which the future 
changes in the economic field are based (Ferri et al., 2019; Fu et al., 2019). Cloud computing affects the provision of services, in the sense that such services can only be accessed remotely and on demand. In other words, cloud computing allows for increased flexibility, which is the main reason for its adoption, and provides a highly efficient big data analysis, affecting all economic actors (Attaran and Woods, 2018; Yoo and Kim, 2018).

Conducting a search of the keywords cloud computing and public sector on the Web of Science, we identified 310 articles published between 2009 and 2021.

By processing the data from the last 10 years in the VOSviewer program, we obtained four interconnected clusters, namely: adoption, model, solution and organization.

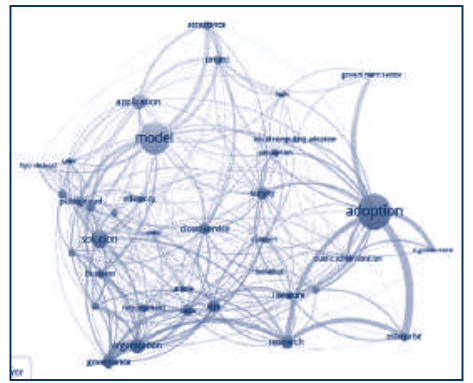

Figure 4. Research directions on the evolution of cloud computing in the public sector

Source: Own elaboration in VOSviewer.

In Figure 5 we can see the individual maps for the keywords identified in the selected articles in the Web of Science.
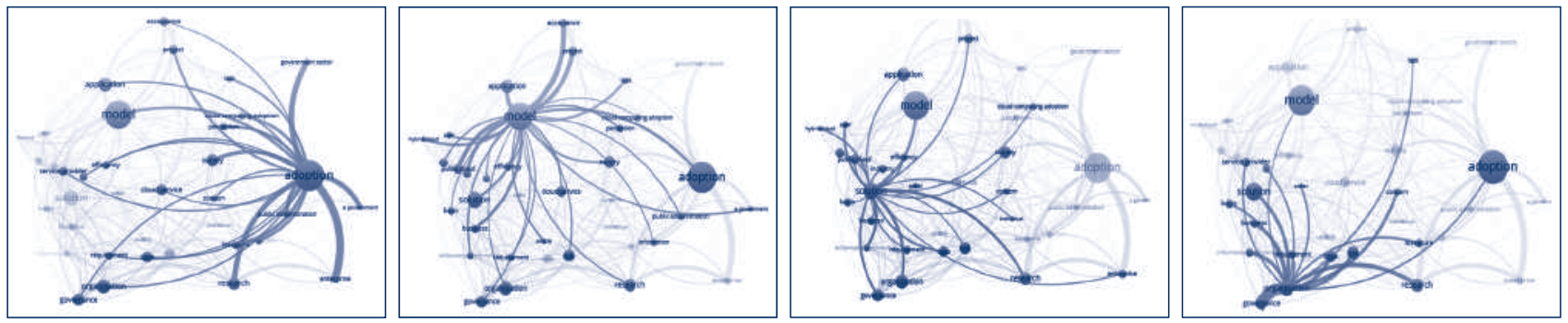

Figure 5. Research directions on the adoption of cloud computing in the public sector, structured on keywords

Source: Own elaboration in VOSviewer.

\section{$\rightarrow$ Research methodology}

In this study, we aim to identify the opportunities and challenges of implementing cloud computing, as well as the ways to overcome them, with a focus on the public sector. The research method used is the qualitative analysis, by documenting, observing and interpreting international and national studies in the field.

In order to achieve this goal, the questions that need clarification are the following:

1. What are the challenges facing the implementation of cloud computing in the public sector?

2. What are the opportunities for implementing cloud computing in the public sector?

3. What are the ways in which the public sector can overcome these challenges?

\section{$\rightarrow$ Digitalization and digital skills}

The European Union prioritizes digitalization, which is a central theme within the Digital Europe Programme, component part of the EU budget for 2021-2027. The aim of this program is "to accelerate the recovery and drive 
the digital transformation of Europe", and the allocated budget is 7.5 billion euros. The Digital Europe Programme "aims to build the strategic digital capacities of the EU and facilitate the widespread deployment of digital technologies to be used by the European citizens, businesses and public administrations". (https://digitalstrategy.ec.europa.eu/en/library/digital-europe-programme-proposed-eu75-billion-funding-2021-2027)

Figure 6 captures the guidelines funded by the European Union, as well as the budget allocated for each component.

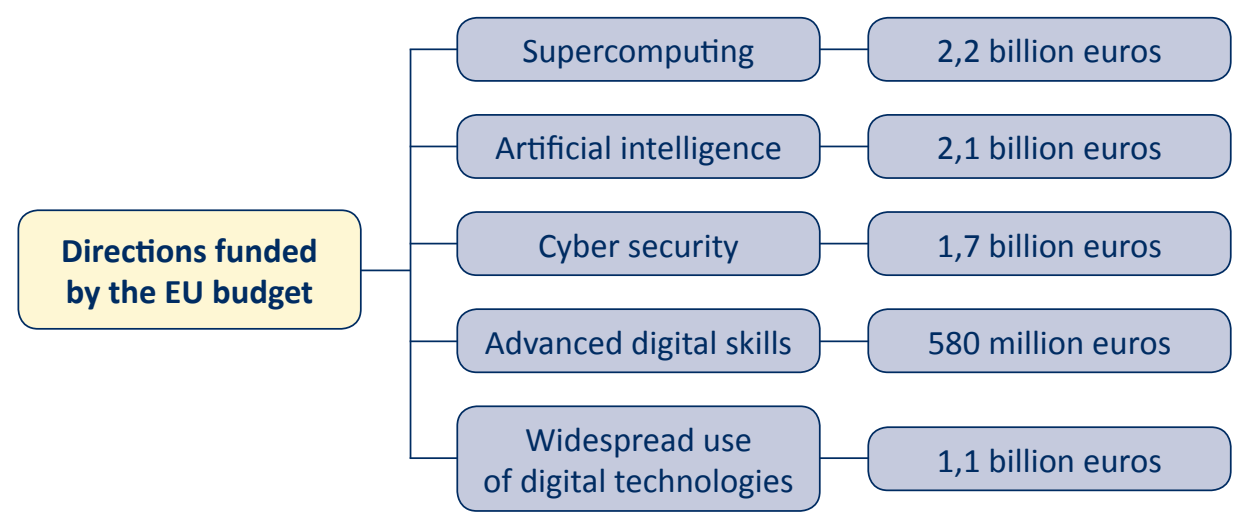

Figure 6. Funding directions provided by the EU budget for the period 2021-2027

Source: https://digital-strategy.ec.europa.eu/en/library/digital-europe-programme-proposed-eu75-billion-funding-2021-2027

As we can see, one of the guidelines for the European Union is represented by the digital competences, and in this respect the European Commission has developed DigComp - The European Digital Competence Framework ever since 2013. Its initial form has been developed, and the 2016 DigComp framework mentions the digital skills that citizens should acquire, structured in five areas, shown in the following figure.
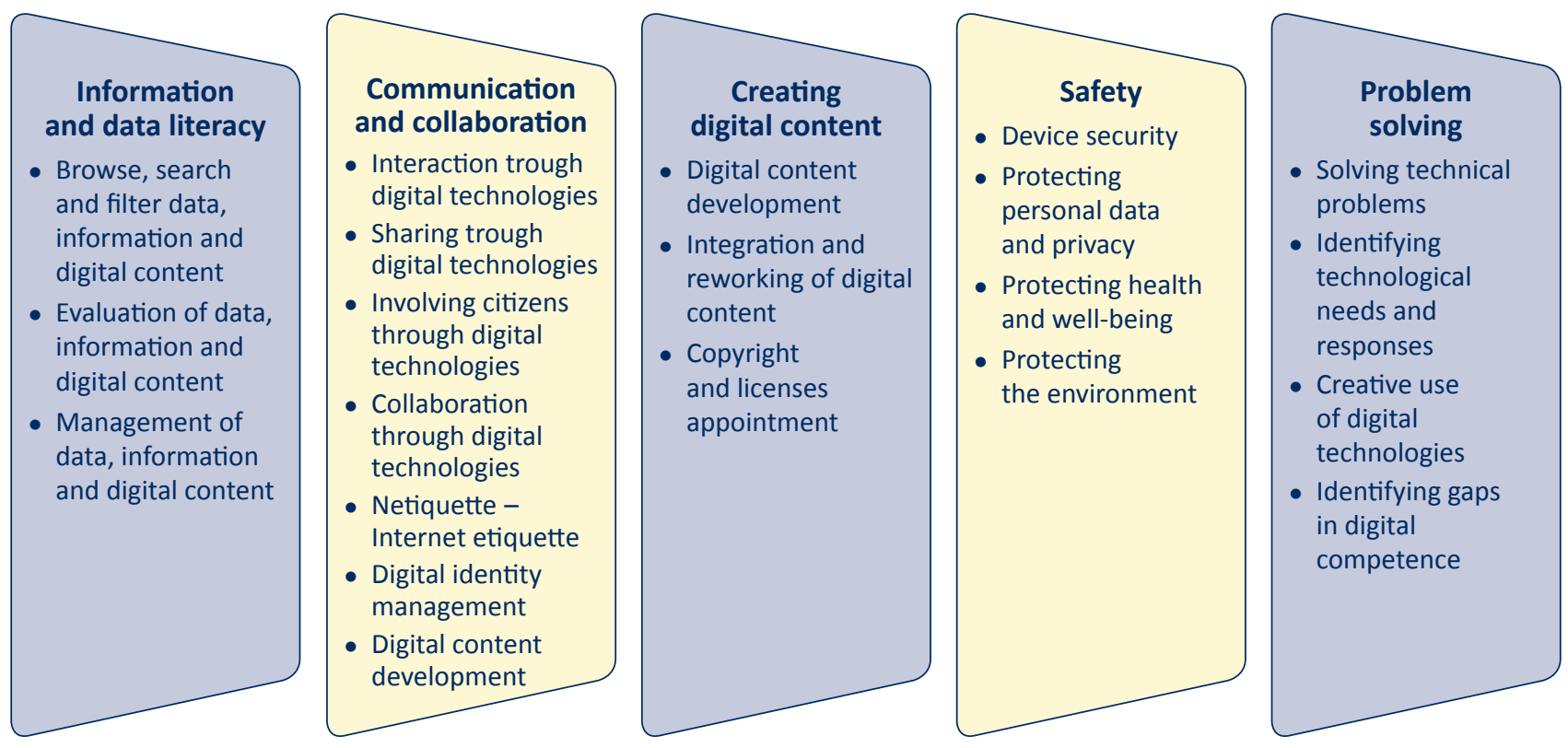

Figure 7. Key areas and related competences according to 2016 DigComp The European Digital Competence Framework for Citizens

Source: EU Science Hub, https://ec.europa.eu/jrc/en/digcomp. 


\section{IT in the public sector}

In our century, modern information technologies have proven their effectiveness and have led government authorities around the world to adopt them. The reason for implementing them stems from their contribution to making the transition from the traditional, inert, bureaucratic organization to an efficiency-oriented institution that provides quality and timely public services to its citizens.

The digitalization of the public sector brings many benefits for citizens, businesses and even for governments. The digitalization of government services can significantly reduce the administrative burden on citizens and businesses, increase transparency regarding government decisions and reduce the corruption risk.

By capitalizing on information technologies, the public sector aims to improve the quality of public services, but also to increase internal efficiency and productivity. Bhisikar (2011) believes that governments are becoming proactive in this area by means of massive investments in IT for improving public services, optimizing internal processes and revitalizing democracy. Nonetheless, the rapid evolution of technologies requires constant investments in infrastructure, whose costs are not negligible and that, most of the time, the public sector cannot afford (Singh and Chandel, 2014). This is the reason why many governments around the world switch to cloud technology, by capitalizing on economies of scale and reducing the technology infrastructure expenses.

\section{$\supset$ Cloud computing}

"Cloud computing is the delivery of computing services - including servers, storage, databases, networking, software, analytics, and intelligence - over the Internet ("the cloud") to offer faster innovation, flexible resources, and economies of scale. You typically pay only for cloud services you use, helping you lower your operating costs, run your infrastructure more efficiently, and scale as your business needs change." (https://azure.microsoft. com/en-us/overview/what-is-cloud-computing/)

According to the National Institute of Standards and Technology (NIST), "cloud computing is a model for enabling ubiquitous, convenient, on-demand network access to a shared pool of configurable computing resources (e.g., networks, servers, storage, applications, and services) that can be rapidly provisioned and released with minimal management effort or service Provider interaction" (https://csrc.nist.gov/glossary/term/cloud_computing).

Cloud computing is considered a real turning point in computer history (Wyld, 2010). The motivation of this statement starts precisely from the use of IT resources. The classic model uses hardware resources purchased by the user from the supplier, being exclusively used on a local infrastructure. Instead, cloud computing allows access to hardware resources as services and not as products, available via the Internet. It allows the remote access to services, and taxing consumers is made similarly to the utility services. Thus, they pay how much they consume, without investing in equipment and their maintenance.

For the natural persons, the use of cloud computing involves accessing e-mail, social networks, document sharing, etc. For organizations, switching to the cloud has a higher economic value due to the cost savings resulting from not acquiring hardware and software. As regards the government authorities, things are not so simple, even if the adoption of the technology is particularly attractive, both in terms of the changing requirements for IT and the difficult economic conditions.

The benefits of adopting cloud computing in the public sector are suggestively captured in Figure 8.

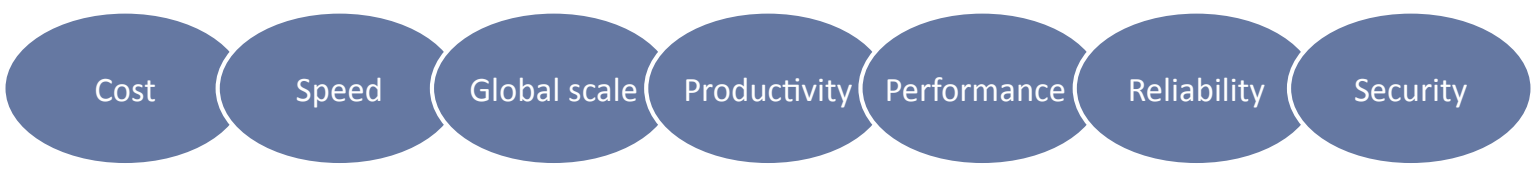

Figure 8. Benefits of adopting cloud computing in the public sector

Source: https://azure.microsoft.com/en-us/overview/what-is-cloud-computing/\#benefits 
By adopting cloud computing, government authorities are able to increase productivity, speed of information transmission, data reliability, and increase the security of information transmitted or stored, all at minimal cost.

Agarwal et al. (2020) believe that before adopting cloud computing in the public sector, leaders should find the answer to their questions. The aim is to identify the areas where the adoption of cloud computing would have the greatest impact.

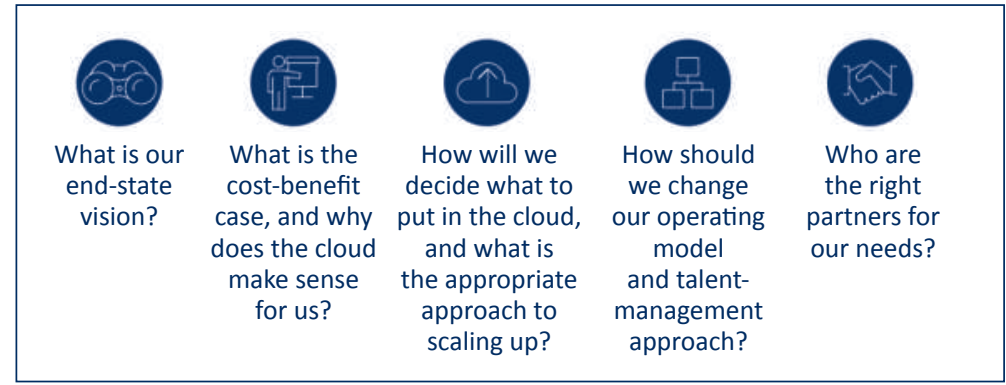

Figure 9. Questions that public institutions should answer before adopting cloud computing

Source: Agarwal et al., 2020.

By identifying these answers, the public sector can adopt the best strategy in order to take full advantage of the benefits of cloud migration now and in the future.

The challenges of adopting cloud computing in the public sector are summarized in Figure 10.

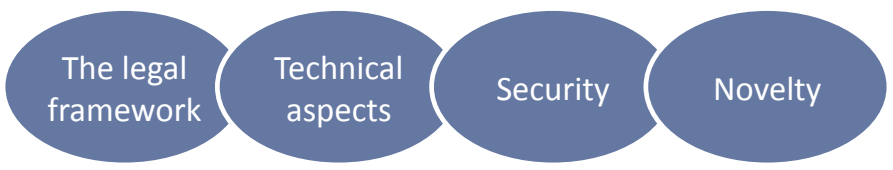

Figure 10. Challenges of adopting cloud computing in the public sector

Source: Own processing.

The major challenge of implementing cloud computing in the public sector is the legal framework. Most countries do not have an appropriate legislation governing the availability, accessibility, confidentiality and security of public data, and this is absolutely vital in the public sector. The existence of a regulatory framework is required by the fact that any security breach may be a threat to citizen security and, according to the level of confidentiality, may also be considered a threat to national sovereignty.

Another challenge is the novelty. In the public domain, the novelties and changes are received with skepticism. Very few public institutions have adopted cloud computing, and leading by example cannot be applied yet in this sector. Although many countries, such as the United States, Canada, the United Kingdom, Norway, Sweden, Denmark, South Korea, Japan, Taiwan, Singapore, Australia and New Zealand, have already implemented cloud services, the global ratio of the public institutions that have adopted this technology is still very small.

\section{Conclusions}

During this period, we are present in the expansion of digitalization in all areas of economic and social life. The public sector is implicitly affected by this expansion. 
At European level, the issue of digitalization plays an important role, as evidenced by the EU budget for digitalization, amounting to 7.5 billion euros.

Part of digitalization, the adoption of cloud computing brings a change of perception and mentality. The benefits of its implementation in the public domain are obvious and include lower costs, increased working speed, global scale, increased productivity, performance, reliability and security.

However, at the level of a public entity, the risks and challenges are commensurate with its responsibility. Thus, the adoption of this technology should be very well regulated by law, especially since any security breach might have a direct and significant impact on citizens.

As we presented in this paper, the benefits of implementing cloud computing in the public sector are far superior to the challenges.

\section{References}

1. Agarwal, R., Khan, N., Santos, L., Shenai, G. (2020), How Public-Sector Tech Leaders Can Speed Up the Journey to the Cloud, https://www.mckinsey.com/industries/public-and-social-sector/our-insights.

2. Attaran, M., Woods, J. (2018), Cloud Computing Technology: Improving Small Business Performance Using the Internet, Journal of Small Business \& Entrepreneurship, Vol. 13, No. 6, pp. 495-519, DOI: 10.1080/08276331.2018.1466850.

3. Bhisikar, A. (2011), G-Cloud: New Paradigm Shift for Online Public Services, International Journal of Computer Applications, Vol. 22, No. 8, pp. 24-29.

4. Burns, J., Ezzamel, M., Scapens, R. (1999), Management Accounting Change in the UK, Management Accounting, Vol. 77, No. 3, pp. 28-30.

5. Ferri, L., Spanò, R., Tomo, A. (2019), Cloud Computing in High Tech Startups: Evidence from a Case Study, Technology Analysis \& Strategic Management, Vol. 32, No. 2, pp. 146-157, DOI: 10.108 0/09537325.2019.1641594.

6. Fu, J., Zhang, Z., Lyu, D. (2019), Research and Application of Information Service Platform for Agricultural Economic Cooperation Organization Based on Hadoop Cloud Computing Platform Environment: Taking Agricultural and Fresh Products as an Example, Cluster Computing, Vol. 22, No. 6, pp. 14689-14700, DOI: 10.1007/s10586-018-2380-z.

7. Morgan, L., Conboy, K. (2013), Factors Affecting the Adoption of Cloud Computing: An Exploratory Study, in Proceedings of the 21st European Conference on Information Systems, Utrecht, Olanda.

8. Mutkoski, S. (2015), National Cloud Computing Principles: Guidance for Public Sector Authorities Moving to the Cloud, in 2015 IEEE International Conference on Cloud Engineering, Tempe, AZ, USA, pp. 404-409, DOI: 10.1109/IC2E.2015.104.

9. Piswanger, C.-M., Strick, L. (2017), European Innovation Procurement "Pre-Commercial-Procurement" and Cloud Computing by Reference to the Research Project "Cloud for Europe", in 2017 Fourth International Conference on eDemocracy \& eGovernment (ICEDEG), Quito, Ecuador, pp. 161-166, DOI: 10.1109/ ICEDEG.2017.7962527.

10. Russel, K., Siegel, G. (1999), Counting More, Counting Less, Strategic Finance, Vol. 81, No. 3, pp. 38-44.

11. Scapens, R.W., Burns, J.E., Ezzamel, M., Baldvinsdottir, G. (2003), The Future Direction of UK Management Accounting Practice, CIMA, London.

12. Singh, V.J., Chandel, A. (2014), Evolving E-Governance through Cloud Computing Based Environment, International Journal of Advanced Research in Computer and Communication Engineering, Vol. 3, No. 4, pp. 6188-6191. 
13. Wyld, D.C. (2010), The Cloudy Future of Government IT: Cloud Computing and the Public Sector Around the World, International Journal of Web \& Semantic Technology, Vol. 1, No. 1, pp. 1-20.

14. Yoo, S.-K., Kim, B.-Y. (2018), A Decision-Making Model for Adopting a Cloud Computing System, Sustainability, Vol. 10, No. 8, pp. 29-52, DOI: 10.3390/su10082952.

15. Yu, L. (2020), Analysis on the Demand Evolution of Cloud Accounting Information System in the Era of Big Data, in 2020 5th International Conference on Smart Grid and Electrical Automation (ICSGEA), pp. 350-353, DOI: 10.1109/ICSGEA51094.2020.00081.

16. https://azure.microsoft.com/en-us/overview/what-is-cloud-computing

17. https://csrc.nist.gov/glossary/term/cloud_computing

18. https://digital-strategy.ec.europa.eu/en/library/digital-europe-programme-proposed-eu75-billionfunding-2021-2027

19. https://ec.europa.eu/jrc/en/digcomp

20. https://wcs-webofknowledge-com.am.e-nformation.ro/RA/analyze.do

$\stackrel{4}{4}$ Acknowledgment: This paper is based on the results of the research co-financed by the project "DECIDE-Development Through Entrepreneurial Education and Innovative Doctoral and Postdoctoral Research", code POCU/380/6/13/125031, project co-financed by the European Social Fund through the Operational Programme Human Capital 2014-2020. 